\title{
Identification of a haem-utilization protein (Hup) in Haemophilus influenzae
}

\begin{abstract}
Correspondence
Terrence L. Stull

terrence-stull@ouhsc.edu
\end{abstract}

Received 15 April 2004

Revised 13 August 2004

Accepted 25 August 2004

\author{
Daniel J. Morton, ${ }^{1}$ Ann Smith, ${ }^{3}$ Zhen Ren, ${ }^{1} \dagger$ Larissa L. Madore, ${ }^{1}$ \\ Timothy M. VanWagoner, ${ }^{1}$ Thomas W. Seale, ${ }^{1}$ Paul W. Whitby ${ }^{1}$ \\ and Terrence L. Stull ${ }^{1,2}$ \\ 1,2Departments of Pediatrics ${ }^{1}$ and Microbiology/Immunology ${ }^{2}$, University of Oklahoma Health \\ Sciences Center, Oklahoma City, OK 73104, USA
${ }^{3}$ School of Biological Sciences, University of Missouri-Kansas City, Kansas City, MO 64110 , USA

\begin{abstract}
Haemophilus influenzae has an absolute growth requirement for a porphyrin source. This growth requirement can be satisfied in vitro by haem, haemoglobin or the haemoglobin-haptoglobin, haem-haemopexin and haem-albumin complexes. A family of proteins, termed the Hgp proteins, which are essential for utilization of the haemoglobin-haptoglobin complex, has previously been identified. A strain lacking the Hgp proteins also has a residual ability to utilize haemoglobin, indicating that additional moieties contribute to haemoglobin utilization. Using a haemoglobin affinity method an approximately $105 \mathrm{kDa}$ protein was isolated. Mutation of the identified gene in an Hgp null background reduced the ability of the mutant strain to utilize haemoglobin in vitro. The mutation also resulted in a reduced ability to utilize haem, haem-haemopexin, haem-albumin and haemoglobin-haptoglobin, thus identifying a general haem-utilization protein (Hup) in Haemophilus influenzae.
\end{abstract}

\section{INTRODUCTION}

Haemophilus influenzae are fastidious Gram-negative bacteria that cause a range of human infections including otitis media, meningitis, epiglottitis and pneumonia (Foxwell et al., 1998; Sethi \& Murphy, 2001; St Geme, 2001; Turk, 1984). The incidence of meningitis caused by $H$. influenzae strains with the type b capsule has decreased by more than $90 \%$ in industrialized countries following the introduction of vaccines based on the type b capsule (Hviid \& Melbye, 2004; Watt et al., 2003). H. influenzae strains of other capsular serotypes infrequently cause invasive disease, although recent reports indicate an increased incidence of invasive disease caused by $H$. influenzae of capsular serotypes other than $b$ subsequent to the introduction of the type b vaccine (Bajanca et al., 2004; Ribeiro et al., 2003). Strains of $H$. influenzae lacking a capsule (nontypable $H$. influenzae) rarely cause invasive disease but are significant causes of otitis media in children and pneumonia in patients with predisposing conditions (Murphy, 2003; St Geme, 2001; Turk, 1984). Understanding the pathogenic

tPresent address: Amylin Pharmaceuticals, Inc., 9360 Towne Centre Drive, San Diego, CA 92121, USA.

Abbreviation: PPIX, protoporphyrin IX.

The GenBank/EMBL/DDBJ accession numbers for the sequences reported in this paper are AY496274 for strain HI689 and AY525146 for strain E1a. mechanisms of $H$. influenzae disease is important as a basis for treatment and eradication of this pathogen.

Since $H$. influenzae lacks all the enzymes in the biosynthetic pathway for the porphyrin ring, it is unable to synthesize protoporphyrin IX (PPIX), the immediate precursor of haem (Panek \& O’Brian, 2002; White \& Granick, 1963). However, most $H$. influenzae strains possess a gene encoding the enzyme ferrochelatase that mediates insertion of iron into PPIX to form haem (Loeb, 1995; Schlor et al., 2000). Thus, $H$. influenzae has an absolute growth requirement for an exogenous PPIX or haem source (haematin is correctly ferrous PPIX while haemin is ferric PPIX; however, in this paper the term haem is used regardless of iron valency).

Since the only known niche for $H$. influenzae is humans, the organism must have adapted its mechanisms of haem acquisition accordingly. There is no significant source of free PPIX available in the normal human host. Haem is generally intracellular, in the form of haemoglobin or haemcontaining enzymes, and therefore unavailable to invading micro-organisms (Genco \& Dixon, 2001; Griffiths, 1999). Free haemoglobin, derived from lysed erythrocytes, is bound by the serum protein haptoglobin, and the haemoglobinhaptoglobin complex is rapidly cleared by the reticuloendothelial cells of the liver, bone marrow or spleen (Evans et al., 1999; Ward \& Bullen, 1999). Free haem, principally derived from the degradation of methaemoglobin, is bound 
by the serum proteins haemopexin and albumin and cleared from the circulation (Genco \& Dixon, 2001; Peters, 1996). Haemoglobin and the haemoglobin-haptoglobin, haemhaemopexin and haem-albumin complexes, as well as PPIX in the presence of an iron source such as ferritransferrin, can each be utilized by $H$. influenzae as haem sources in vitro (Morton \& Williams, 1989; Schryvers \& Gray-Owen, 1992; Stull, 1987).

A complex array of haem-uptake mechanisms has evolved in $H$. influenzae to ensure acquisition of this essential nutrient (Morton \& Stull, 2004). For example, the $h x u C B A$ gene cluster mediates utilization of low levels of free haem, the haem-haemopexin complex and haemoglobin (Cope et al., $1995,1998,2001)$, as well as the haem-albumin complex (D. J. Morton, L. L. Madore, T. M. VanWagoner, T. W. Seale, P. W. Whitby \& T. L. Stull, unpublished observations), and utilization of ferritransferrin is mediated by the transferrin-binding proteins, Tbp1 and Tbp2 (Gray-Owen \& Schryvers, 1996). We have shown that utilization of haemoglobin-haptoglobin is mediated by a family of haemoglobin/haemoglobin-haptoglobin-binding proteins ( $h g p A, h g p B$ and $h g p C$ in the type b strain HI689) (Jin et al., 1996, 1999; Morton et al., 1999; Ren et al., 1998).

Individual $H$. influenzae strains possess one to four $h g p$ genes (Cope et al., 2000; Morton et al., 1999; Morton \& Stull, 1999). Expression of the proteins encoded by the hgp genes is phase variable due to a length of CCAA nucleotide repeats immediately following the sequence encoding the leader peptide. Alterations in the length of the CCAA nucleotide repeat regions lead to frame-shift mutations and the introduction of stop codons (Ren et al., 1999). While expression of the Hgp proteins is essential for the utilization of the haemoglobin-haptoglobin complex in vitro, mutants lacking the hgp genes retain the ability to utilize haemoglobin albeit at a reduced level (Morton et al., 1999). These data demonstrate that although the Hgp proteins play a role in the utilization of haemoglobin, additional moieties are involved in the utilization of this haem source.

The objective of this study was to identify additional protein(s) involved in the utilization of haemoglobin and/or other potential haem sources by $H$. influenzae. We report the identification of an $H$. influenzae protein involved in the utilization of multiple haem sources that we have designated a haem-utilization protein (Hup).

\section{METHODS}

Bacterial strains, growth conditions and plasmids. The bacterial strains and plasmids used in this study are listed in Table 1. $H$. influenzae type b strain HI689 is a clinical blood isolate and has been previously described (Jin et al., 1996; Musser et al., 1986). Strain HI1717 is a derivative of strain HI689 lacking the hgp genes $(h g p A, h g p B, h g p C)$ and was the subject of a previous report (Morton et al., 1999). H. influenzae was routinely maintained on chocolate agar with bacitracin (BBL) at $37^{\circ} \mathrm{C}$. When necessary, $H$. influenzae was grown on brain heart infusion (BHI) agar (Difco) supplemented with $10 \mu \mathrm{g}$ haem $\mathrm{ml}^{-1}$ and $10 \mu \mathrm{g} \beta$-NAD $\mathrm{ml}^{-1}$ (supplemented BHI; sBHI) and the appropriate antibiotic(s). Haem-deplete growth was performed in BHI broth supplemented only with $10 \mu \mathrm{g} \beta$-NAD ml ${ }^{-1}$ (haem-deplete BHI; hdBHI). $H$. influenzae was transformed to antibiotic resistance using a modification of the static aerobic method of Gromkova et al. (1989) as previously described (Morton et al., 2004).

Haem sources. Human haemoglobin, human haptoglobin (from pooled sera), human serum albumin (HSA) and bovine haemin were purchased from Sigma. Stock haem solutions were prepared at $1 \mathrm{mg}$ haem $\mathrm{ml}^{-1}$ in $0.02 \mathrm{M} \mathrm{NaOH}$. Haemoglobin was dissolved in water immediately before use. Haemoglobin-haptoglobin complexes were prepared as previously described (Morton et al., 1999). Haemalbumin complexes were made by mixing $100 \mu \mathrm{g}$ haem and $20 \mathrm{mg}$ HSA per ml of water as previously described (Stull, 1987).

Rabbit haemopexin was prepared as described previously and the haem-haemopexin complexes were characterized by the typical features of their absorption spectra, which include the prominent shoulder at $290 \mathrm{~nm}$ that appears upon haem binding (Smith, 1985; Smith \& Morgan, 1984).

DNA methodology. Restriction endonucleases were obtained from New England Biolabs and used as directed by the manufacturer. Genomic DNA was isolated using the DNeasy Tissue Kit (Qiagen) as directed by the manufacturer. Plasmid DNA was isolated using Wizard Plus Minipreps DNA purification system (Promega) according to the manufacturer's directions. Sequencing of double-stranded template DNA was performed by automated sequencing on an $\mathrm{ABI}$ Prism model 3700 DNA Analyser at the Recombinant DNA/Protein Resource Facility, Oklahoma State University, Stillwater, OK, USA. Oligonucleotides were synthesized by Qiagen.

Affinity isolation of haemoglobin-binding proteins. Outermembrane proteins were purified and subjected to haemoglobin affinity purification as previously described (Jin et al., 1996). Eluted proteins were separated by SDS-PAGE on $7 \cdot 5 \%$ acrylamide gels using the discontinuous buffer system of Laemmli (1970). Approximately $30 \mu \mathrm{l}$ of protein preparation, representing proteins isolated from approximately $10^{6}$ organisms, was loaded per lane.

$\mathbf{N}$-terminal amino acid sequencing. Affinity-chromatographypurified proteins were separated by SDS-PAGE and transferred to a polyvinyldene difluoride membrane as previously described (Jin et al., 1996). The entire membrane was submitted to the UCLA Medical School Protein Microsequencing Facility for N-terminal amino acid sequencing.

Cloning and sequencing of hup from $\boldsymbol{H}$. influenzae type b strain H1689. Two separate primer pairs (Table 2) were designed for use in the PCR based on the Rd KW20 genomic sequence (Fleischmann et al., 1995). These primer pairs amplified two overlapping fragments encompassing the ORF HI1217 locus. 1217A and 1217REVSQ2 amplified an $\sim 1000 \mathrm{bp}$ product encompassing approximately $800 \mathrm{bp}$ encoding the C-terminal portion of the encoded protein and $200 \mathrm{bp}$ downstream of the gene. Primers 1217SQ2 and 1217SQ101 amplified a product of $\sim 2800$ bp encompassing approximately $2000 \mathrm{bp}$ encoding the $\mathrm{N}$-terminal region of the encoded protein and approximately $800 \mathrm{bp}$ upstream of the gene.

PCRs were performed in a $50 \mu \mathrm{l}$ volume using $100 \mathrm{ng}$ of $H$. influenzae HI689 chromosomal DNA as template, and the reactions contained $2 \mathrm{mM} \mathrm{MgCl}, 200 \mu \mathrm{M}$ of each deoxynucleoside triphosphate (New England Biolabs), $10 \mathrm{pmol}$ of each primer and $2 \mathrm{U}$ of Taq DNA Polymerase (Roche). PCR was carried out for 30 cycles, with each cycle consisting of denaturation at $95^{\circ} \mathrm{C}$ for $1 \mathrm{~min}$, annealing for $1 \mathrm{~min}$ at $58^{\circ} \mathrm{C}$ for primer pair $1217 \mathrm{~A} / 1217 \mathrm{REVSQ} 2$ and $57^{\circ} \mathrm{C}$ for primer pair 1217SQ2/1217SQ101, and primer extension at $72^{\circ} \mathrm{C}$ for $1 \mathrm{~min}$, with 
Table 1. Strains and plasmids

\begin{tabular}{|c|c|c|}
\hline Strain or plasmid & Relevant characteristic $(s)^{\star}$ & Reference or source \\
\hline \multicolumn{3}{|l|}{ Strains } \\
\hline \multicolumn{3}{|l|}{ H. influenzae } \\
\hline HI689 & Type b & Musser et al. (1986) \\
\hline HI1714 & HI689, $\Delta h g p A \Delta h g p B, \mathrm{Rb}^{\mathrm{r}} \mathrm{Tc}^{\mathrm{r}}$ & Morton et al. (1999) \\
\hline HI1717 & HI689, $\Delta h g p A \Delta h g p B \Delta h g p C, \mathrm{Rb}^{\mathrm{r}} \mathrm{Tc}^{\mathrm{r}} \mathrm{Sp}^{\mathrm{r}}$ & Morton et al. (1999) \\
\hline HI1737 & HI689 $\Delta h u p, \mathrm{Zeo}^{\mathrm{r}}$ & This study \\
\hline HI1738 & HI1717 $\Delta h u p, Z_{e}{ }^{r}$ & This study \\
\hline HI1955 & HI1737, pDJM367, $\mathrm{Zeo}^{\mathrm{r}} \mathrm{Cm}^{\mathrm{r}}$ & This study \\
\hline HI1953 & HI1738, pDJM367, $\mathrm{Rb}^{\mathrm{r}} \mathrm{Tc}^{\mathrm{r}} \mathrm{Sp}^{\mathrm{r}} \mathrm{Zeo}^{\mathrm{r}} \mathrm{Cm}^{\mathrm{r}}$ & This study \\
\hline E1a & Type b & Stull et al. (1984) \\
\hline \multicolumn{3}{|l|}{ E. coli } \\
\hline TOP10 & Used for cloning in pCR2.1-TOPO and pUC19N & Invitrogen \\
\hline \multicolumn{3}{|l|}{ Plasmids } \\
\hline pCR2.1-TOPO & Plac, lacZ $\alpha, \operatorname{Kan}^{r} \mathrm{Amp}^{\mathrm{r}}$, ColE1 origin, F1 origin, T7 promoter & Invitrogen \\
\hline pUC19N & pUC19 with a NotI site added at the HindIII end of the polylinker & Tartof \& Hobbs (1988) \\
\hline pSU2718 & E. coli-H. influenzae shuttle vector, lac $\mathrm{Z} \alpha, \mathrm{Cm}^{\mathrm{r}}, \mathrm{p} 15 \mathrm{a}$ ori & Martinez et al. (1988) \\
\hline pEM7/Zeo & $\begin{array}{l}\text { Plasmid expressing } \mathrm{Zeo}^{\mathrm{r}}\left(\mathrm{Sh} \text { ble) using the bacterial EM7 promoter; the Zeo }{ }^{\mathrm{r}}\right. \\
\text { cassette is flanked by polylinkers to allow excision of the resistance marker }\end{array}$ & Invitrogen \\
\hline p1217UD & $\begin{array}{l}\text { pUC19N carrying an } \sim 1100 \text { bp PCR product corresponding to a region upstream } \\
\text { of hup and an } \sim 1100 \text { bp product corresponding to a region downstream of } \\
\text { hup with a unique BamHI site between the two inserts }\end{array}$ & This study \\
\hline p1217UD-ZEO & $\begin{array}{l}\text { p1217UD with the } \sim 700 \mathrm{bp} \mathrm{Zeo}^{\mathrm{r}} \text { marker from pEM7/Zeo inserted at the unique } \\
\text { BamHI site }\end{array}$ & This study \\
\hline pDJM359 & $\begin{array}{l}\text { pCR2.1-TOPO carrying an } \sim 3200 \text { bp PCR product encompassing the hup coding } \\
\text { sequence and upstream and downstream regions }\end{array}$ & This study \\
\hline pDJM367 & pSU2718 carrying the 3200 bp PCR product from pDJM359 & This study \\
\hline
\end{tabular}

${ }^{*} \mathrm{Amp}^{\mathrm{r}}$, ampicillin resistance $\left(50 \mu \mathrm{g}\right.$ ampicillin $\mathrm{ml}^{-1}$ in E. coli); $\mathrm{Cm}^{\mathrm{r}}$, chloramphenicol resistance $\left(1.5 \mu \mathrm{g}\right.$ chloramphenicol $\mathrm{ml}^{-1}$ in $\mathrm{H}$. influenzae and $50 \mu$ g chloramphenicol $\mathrm{ml}^{-1}$ in E. coli); $\mathrm{Kan}^{\mathrm{r}}$, kanamycin resistance $\left(50 \mu \mathrm{g}\right.$ kanamycin $\mathrm{ml}^{-1}$ in E. coli); Sp $\mathrm{p}^{\mathrm{r}}$, spectinomycin resistance $(200 \mu \mathrm{g}$ spectinomycin $\mathrm{ml}^{-1}$ in $\mathrm{H}$. influenzae); $\mathrm{Tc}^{\mathrm{r}}$, tetracycline resistance $\left(3 \mu \mathrm{g}\right.$ tetracycline $\mathrm{ml}^{-1}$ in $\mathrm{H}$. influenzae); Zeo ${ }^{\mathrm{r}}$, zeocin resistance $(50 \mu \mathrm{g}$ zeocin $\mathrm{ml}^{-1}$ in H. influenzae and $100 \mu \mathrm{g}$ zeocin $\mathrm{ml}^{-1}$ in E. coli).

one final extension of $30 \mathrm{~min}$. PCR products of the expected size were obtained from both PCRs and were successfully cloned into the TA cloning vector pCR2.1-TOPO. The insert DNA sequence derived from at least two independent PCRs was determined by automated sequencing. Discrepancies were resolved by the sequencing of a third independent PCR product across the appropriate region.

Table 2. Primers

\begin{tabular}{|ll|}
\hline Primer & \multicolumn{1}{c|}{ Sequence $\left(\mathbf{5}^{\prime} \mathbf{- 3}^{\prime}\right)$} \\
\hline 1217 REVSQ2 & CTCAAGACGATGTGCTAGG \\
1217A & GTTCGAGCAATTTCTGATGG \\
1217 SQ2 & TAGCACATCGTCTTGAGTG \\
1217 SQ101 & CTTCTTTACGTACCCGC \\
$1217-1$ & GGATCCTTATCCATTTTATTAAGAGG \\
$1217-2$ & CTGCAGGCTTATTTATTTCTGTATGGG \\
$1217-3$ & GGATCCGCATAGCTAATAGCTATGCC \\
$1217-4$ & GAATTCCGATAACCAGTTTAGCG \\
$1217-5$ & GAATTCCTTAGTACCTTTATTTTATAATC \\
$1217-6$ & GGATCCCTTAGTACCTTTATTTTATA \\
\end{tabular}

Construction of an hup deletion mutant. Complete deletion of hup in strains HI689 and HI1717 was achieved essentially as previously described for deletion of the hgp genes (Morton et al., 1999). Four primers (Table 2) for use in the PCR were designed based on the available $H$. influenzae strain Rd KW20 genomic sequence (Fleischmann et al., 1995) to delete hup in strain HI689. Primers 1217-1 and 1217-2 were designed to amplify a product of approximately $1100 \mathrm{bp}$ upstream of hup and, respectively, add BamHI and PstI sites to the ends of the amplicon to allow for subsequent directional subcloning. Primers 1217-3 and 1217-4 were designed to amplify an approximately 1100 bp product downstream of hup and, respectively, add BamHI and EcoRI to the ends of the amplicon to allow for directional subcloning.

PCR was carried out as described above but with annealing for $1 \mathrm{~min}$ at $53^{\circ} \mathrm{C}$ for primer pair $1217-1 / 1217-2$ and at $47^{\circ} \mathrm{C}$ for primer pair 1217 3/1217-4. PCR products of the expected size were obtained from both PCRs and were successfully cloned into the TA cloning vector pCR2.1TOPO. The cloned amplicon from each reaction was confirmed as correct by automated DNA sequencing. Utilizing the engineered restriction sites, the PCR products were successively subcloned into pUC19N to yield p1217UD. Plasmid p1217UD thus comprised upstream and downstream sequences of HI1217 abutting each other, with a unique BamHI site engineered between the upstream and downstream regions. The zeocin-resistance marker from pEM7/Zeo 
was excised by digestion with BamHI and BglII and cloned into the unique BamHI site of p1217UD to yield p1217UD-ZEO. Competent $H$. influenzae was transformed with p1217UD-ZEO and selected on chocolate agar with zeocin spread on the surface of the plate. The initial selection of recombinant $H$. influenzae was at $25 \mu \mathrm{g}$ zeocin $\mathrm{ml}^{-1}$, with subsequent subculture of potential transformants at $50 \mu \mathrm{g}$ zeocin $\mathrm{ml}^{-1}$. Correct chromosomal rearrangements were confirmed by the molecular size of a PCR product resolved on an agarose gel (data not shown).

Complementation of mutant strains. To complement the deletion of hup in the mutant strains a plasmid was constructed carrying the entire hup gene. A $3200 \mathrm{bp}$ PCR product, encompassing the entire hup coding sequence and $280 \mathrm{bp}$ upstream of the start codon and $150 \mathrm{bp}$ downstream of the stop codon, was amplified from HI689 chromosomal DNA using primers 1217-5 and 1217-6 (annealing at $50^{\circ} \mathrm{C}$ for $1 \mathrm{~min}$, extension for $2 \mathrm{~min}$ ). An amplicon of the expected size was cloned into pCR2.1-TOPO to yield pDJM359 and confirmed by automated DNA sequencing. pDJM359 was digested with $K p n I$ and $S p h \mathrm{I}$ and the band corresponding to the chromosomally derived insert was ligated to KpnI/SphI-digested pSU2718, a shuttle vector with the p15a origin of replication that allows establishment of the plasmid in $H$. influenzae, to yield pDJM367. pDJM367 was confirmed by automated DNA sequencing, and was electroporated into $H$. influenzae hup deletion mutant strains to yield the corresponding merodiploid strains. Electroporation of $H$. influenzae was carried out as previously described (VanWagoner et al., 2004) and transformants were selected on $1.5 \mu \mathrm{g}$ chloramphenicol $\mathrm{ml}^{-1}$.

Growth studies with $\boldsymbol{H}$. influenzae. $H$. influenzae was grown for 12-14 h on chocolate agar with bacitracin, and these 12-14 h cultures were used to inoculate $10 \mathrm{ml}$ hdBHI cultures that were incubated for $4 \mathrm{~h}$ at $37^{\circ} \mathrm{C}$ with shaking ( 175 r.p.m.). The $4 \mathrm{~h}$ cultures were pelleted by centrifugation, washed once in $0 \cdot 1 \%(\mathrm{w} / \mathrm{v})$ gelatin in PBS and resuspended to an optical density at $605 \mathrm{~nm}$ of 0.5 in $0 \cdot 1 \%(\mathrm{w} / \mathrm{v})$ gelatin in PBS. One millilitre of the bacterial suspension was diluted in $5 \mathrm{ml}$ of $0.1 \%(\mathrm{w} / \mathrm{v})$ gelatin in PBS, and this final bacterial suspension was used to inoculate fresh hdBHI $(0 \cdot 1 \%$, $\mathrm{v} / \mathrm{v}$, inoculum to give an approximate initial concentration of 200000 c.f.u. $\mathrm{ml}^{-1}$ ) supplemented as appropriate. Viable counts were performed on all cultures at time zero to ensure that all inocula were comparable (statistical comparisons were made using Student's $t$-test; no inocula were statistically different). Cultures were incubated at $37^{\circ} \mathrm{C}$ with shaking (175 r.p.m.). Growth was monitored to stationary phase by measurement of the $\mathrm{OD}_{605}$ with a Shimadzu UV-1201S spectrophotometer. Growth studies were performed in triplicate a minimum of twice for each condition. All growth studies included a negative control in hdBHI with no added haem source; no strain exhibited any increase in $\mathrm{OD}_{605}$ in this negative control test.

Animals. Specific-pathogen-free (SPF) timed-pregnant SpragueDawley rats (Harlan Sprague-Dawley) were received approximately 5 days prior to giving birth. These pregnant females were singlehoused on hardwood litter with ad libitum access to water and a standard pelleted food (Purina Lab Rodent Diet 5001). They were maintained on a $12 \mathrm{~h}$ light-dark cycle in separate forced-air cubicles in a bio-containment facility to prevent cross-contamination. Newborn pups from different mothers were pooled and randomly reassigned to the mothers ( $n=10$ pups per female). The protocol for usage of animals in this study was reviewed and approved by the Institutional Animal Use and Care Committee of the University of Oklahoma Health Sciences Center.

Infection of animals, collection of blood samples and quantification of bacteraemia. The infant rat model for haematogenous meningitis following intraperitoneal infection with $H$. influenzae
(Smith et al., 1973) was used to compare the abilities of strains to cause bacteraemia. The inoculum was prepared as follows. $H$. influenzae was incubated for $18 \mathrm{~h}$ at $37^{\circ} \mathrm{C}$ on chocolate agar containing bacitracin. A loopful of these cells was used to inoculate $5 \mathrm{ml}$ hdBHI. These broth cultures were incubated at $37^{\circ} \mathrm{C}$ with gentle rotation for approximately $4 \mathrm{~h}$ until moderately turbid. Bacteria were pelleted by centrifugation, washed once with PBS containing $0 \cdot 1 \%(\mathrm{w} / \mathrm{v})$ gelatin, and the pelleted cells were resuspended in the same buffer. The suspension was adjusted to an $\mathrm{OD}_{605}$ of 0.5 and then diluted serially in the same solution to provide the standard inoculum ( 200 c.f.u. in $100 \mu \mathrm{l})$ that was injected intraperitoneally into 5-day-old rat pups. To determine the actual infective dosage, $100 \mu \mathrm{l}$ aliquots of the inoculum were plated on chocolate agar containing bacitracin.

At $24 \mathrm{~h}$ intervals pups were examined for symptoms of infection, and blood specimens $(50 \mu \mathrm{l})$ were obtained. Bacteraemia was quantified using a modification of the track-dilution procedure of Jett et al. (1997). Serial dilutions $\left(0\right.$ to $\left.10^{-5}\right)$ of freshly drawn whole-blood specimens were made with PBS containing $0 \cdot 1 \%(\mathrm{w} / \mathrm{v})$ gelatin. Aliquots of $10 \mu \mathrm{l}$ from each dilution were plated in triplicate on chocolate agar plus bacitracin and incubated at $37^{\circ} \mathrm{C}$ for $24 \mathrm{~h}$ prior to counting.

Statistics. Statistical comparisons of growth between strains under the same growth conditions were assessed using the Kruskal-Wallis test. In some cases the analysis was performed over the entire growth curve and in others only over the period of active growth as specified in the text. Analyses were performed using Analyse-It for Microsoft Excel v1.71 (Analyse-It Software).

For in vivo studies bacteraemic titres are expressed as means $\pm S D$ typically from groups of 10 animals. Statistical comparisons of mean bacteraemic titres between two groups of animals infected with different strains were assessed with the unpaired Student's $t$-test. Analyses were performed with SigmaStat software (SPSS). A $P$ value $<0.05$ was taken as statistically significant in all analyses.

\section{RESULTS AND DISCUSSION}

\section{Isolation and $\mathbf{N}$-terminal amino acid sequencing of haemoglobin-binding proteins}

We previously identified a family of haemoglobin/ haemoglobin-haptoglobin-binding proteins in H. influenzae (Jin et al., 1999; Morton et al., 1999; Ren et al., 1998). Different strains of $H$. influenzae possess different complements of these haemoglobin/haemoglobin-haptoglobinbinding proteins (HgpA, HgpB and HgpC in H. influenzae type b strain HI689) (Cope et al., 2000; Morton et al., 1999). Complete deletion of the Hgp complement of $H$. influenzae strains renders the mutant strain unable to utilize haemoglobin-haptoglobin complexes as a haem source, though still able to utilize haemoglobin as a haem source (Morton et al., 1999).

In order to identify additional potential haemoglobinutilization proteins an affinity isolation protocol was used with haemoglobin as the primary ligand. The affinity isolation protocol was performed on strain HI1714, a derivative of strain HI689 with complete deletion of $h g p A$ and $h g p B$ and thus retaining expression of only HgpC (Morton et al., 1999). Strain HI1714 was selected in order to 


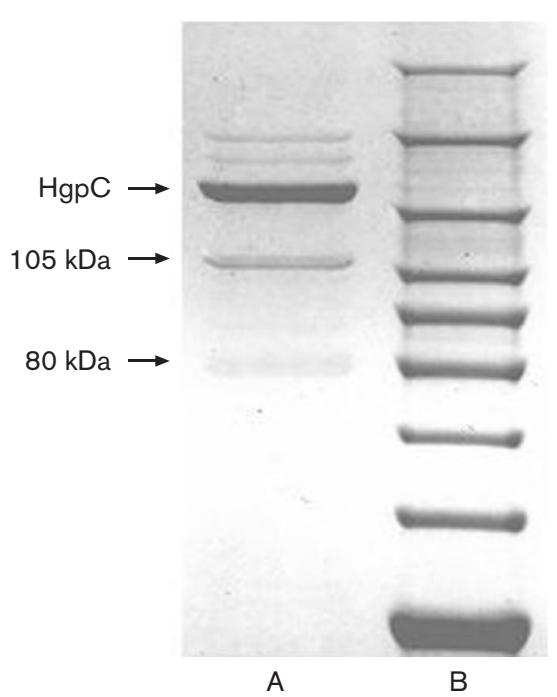

Fig. 1. SDS-PAGE $(7 \cdot 5 \%)$ gel stained with Coomassie blue. Lanes: A, affinity-purified outer-membrane proteins from the $H$. influenzae hgpA/hgpB double mutant strain HI1714; $\mathrm{B}$, BenchMark Protein Ladder (Invitrogen). Arrows point to: the $120 \mathrm{kDa}$ band corresponding to $\mathrm{HgpC}$; an approximately $105 \mathrm{kDa}$ affinity purified band; an approximately $80 \mathrm{kDa}$ affinity purified band. Molecular masses of the BenchMark protein ladder are from top to bottom 220, 160, 120, 100, 90, 80, 70, 60 and $50 \mathrm{kDa}$.

use $\mathrm{HgpC}$ as an internal control for the affinity isolation procedure; the Hgp proteins are efficiently purified in the haemoglobin affinity isolation protocol (Jin et al., 1999; Ren et al., 1998).

Strain HI1714 yielded two major bands of approximately $120 \mathrm{kDa}$ and $105 \mathrm{kDa}$ and three minor bands (one at approximately $80 \mathrm{kDa}$ and two in the $150-160 \mathrm{kDa}$ range) in the affinity isolation protocol (Fig. 1). The $120 \mathrm{kDa}$ protein corresponded, based on size, to HgpC, and was the most prominent band. The four additional purified bands were submitted for $\mathrm{N}$-terminal amino acid sequencing. The two high-molecular-mass minor proteins yielded no usable amino acid sequence. The $80 \mathrm{kDa}$ protein yielded an amino acid sequence of GQVITIGNERFR(X)PETLFQP, which was determined using BLASTP and TBLASTN searches (www.ncbi.nlm.nih.gov/blast) to be $100 \%$ homologous to an internal fragment of actin; no homologous gene products were identified in any available $H$. influenzae genomic sequence and the $80 \mathrm{kDa}$ protein may represent a contaminant derived from the growth medium.

The approximately $105-\mathrm{kDa}$ protein yielded an amino acid sequence of EETLGIDVVEKISNDKKP. This experimentally determined $\mathrm{N}$-terminal amino acid sequence was identical to the processed amino terminus encoded by the ORF designated HI1217 from the H. influenzae Rd KW20 genome sequence (Fleischmann et al., 1995). The predicted product of HI1217 from Rd KW20 consists of 886 amino acids preceded by a 27-residue leader or signal peptide. The molecular mass of the mature protein was calculated to be $99878 \mathrm{Da}$. The product of the ORF HI1217 was originally designated a putative transferrin-binding protein (Fleischmann et al., 1995); however, this designation is unlikely to be accurate. Strain Rd KW20 contains an operon (HI0994 and HI0995) that encodes the well-characterized two-protein complex (TbpA and $\mathrm{TbpB}$ ) involved in transferrin acquisition by $H$. influenzae (Fleischmann et al., 1995; Gray-Owen \& Schryvers, 1996), and there is no evidence for multiple transferrin-acquisition pathways in $H$. influenzae. In addition, the protein putatively encoded by HI1217 from Rd KW20 exhibits only $17 \cdot 3 \%$ identity to TbpA (encoded by HI0995) of Rd KW20, while TbpA proteins of five additional $H$. influenzae strains exhibit 92.9 to $94.9 \%$ identity with TbpA of Rd KW20 (Loosmore et al., 1996). However, HI1217 contains sequences homologous to conserved domains associated with TonBdependent proteins and iron-acquisition proteins as determined using the Conserved Domain Database (CDD v. 1.63) (www.ncbi.nlm.nih.gov/structure/cdd/cdd.shtml) (Marchler-Bauer et al., 2003). In all subsequent discussions the ORF HI1217 and its homologues are referred to as hup (haem-utilization protein).

Since the predicted product of hup has significant homology to other bacterial iron- and/or haem-acquisition-associated proteins and was purified in a haemoglobin affinity purification protocol, we cloned and determined the DNA sequence of the hup homologue from strain HI689. The sequence data revealed an encoded protein of 919 amino acids with a 27 amino acid leader sequence predicted using SignalP 2.0 (www.cbs.dtu.dk/services/SignalP). The mature protein of 892 amino acids had a predicted molecular mass of $100990 \mathrm{Da}$.

Using the sequence alignment application Align $\mathrm{X}$ of the Vector NTI suite v. 8 (Informax), protein sequence alignments between the mature proteins encoded by hup in strains HI689 and Rd KW20 showed 90.3\% similarity and $88.5 \%$ identity. The hup gene homologue from type b strain Ela was also cloned and sequenced; analysis of the gene revealed that it encodes a mature protein of 913 amino acids with a predicted molecular mass of $102800 \mathrm{Da}$ with $90 \%$ similarity and $89 \%$ identity to the strain HI689 homologue.

Additional hup sequences are available from two recently sequenced nontypable $H$. influenzae strains. The gene from strain HI3224A (www.micro-gen.ouhsc.edu) encodes a mature protein of 891 amino acids with a molecular mass of $100500 \mathrm{Da}$, and $90.9 \%$ similarity and $88.8 \%$ identity to the homologous strain HI689 protein; that from strain R2846 (www.genome.washington.edu/uwgc/) encodes a protein of 907 amino acids and $102000 \mathrm{Da}$, with $89 \cdot 4 \%$ similarity and $87.9 \%$ identity to the HI689 protein.

Hup homologues thus are widespread across the species and show high levels of conservation at the amino acid level. 
Such a widespread and highly conserved outer-membrane protein may represent a potential vaccine candidate for prevention of $H$. influenzae disease.

The predicted protein is significantly homologous to putative TonB-dependent outer-membrane receptors from other bacterial species. One such protein from Neisseria meningitidis is designated TdfH (TonB-dependent family protein) (Turner et al., 2001). Td $\overline{\mathrm{fH}}$ was identified based on homology to known TonB-dependent proteins including the haemophore receptor HasR of Serratia marcescens; however, analysis of an isogenic tdfH mutant and expression of the protein in an Escherichia coli hemA mutant failed to demonstrate any role for the protein in haem utilization (Turner et al., 2001). TdfH sequences from three N. meningitidis strains show approximately $63 \%$ similarity and $51 \%$ identity to Hup from HI689. Additional homologous proteins derived from available bacterial genome sequences are from Neisseria gonorrhoeae (64\% similarity, $52 \%$ identity), Actinobacillus actinomycetemcomitans (68\% similarity, $56 \%$ identity), H. somnus ( $45 \%$ similarity, $33 \%$ identity) and Campylobacter jejunii (42\% similarity, $31 \%$ identity). Although each of these proteins is homologous to TonB-dependent receptors, no function(s) have been experimentally determined for any of them.

\section{Growth characteristics of hup deletion mutants}

Since hup was isolated in a haemoglobin affinity purification protocol and showed significant homology to other putative iron/haem-acquisition-related proteins, the potential role of the protein in haemoglobin utilization was investigated. A complete hup deletion mutant of strain HI689 was constructed and designated HI1737. Strains HI689 and HI1737 were compared in growth studies for their ability to utilize haemoglobin as a sole haem source. No statistically significant differences in growth rate or in the final density of the culture were seen between the two strains at haemoglobin concentrations of $1 \mu \mathrm{g} \mathrm{ml}^{-1}$ and $2 \mu \mathrm{g} \mathrm{ml}^{-1}$ (data not shown). These results were not surprising since we have previously demonstrated a role for the Hgp proteins of $H$. influenzae in the utilization of haem from haemoglobin (Morton et al., 1999). In view of this role of the Hgp proteins in the utilization of haemoglobin a complete hup deletion mutation was constructed in a previously constructed derivative of strain HI689 lacking the hgp genes (Morton et al., 1999).

The hgp deletion strain (HI1717) and the hgp hup deletion mutant (HI1738) were compared for their ability to utilize haemoglobin. At both $1 \mu \mathrm{g}$ haemoglobin $\mathrm{ml}^{-1}$ and $2 \mu \mathrm{g}$ haemoglobin $\mathrm{ml}^{-1}$ strain HI1738 consistently exhibited a significantly reduced ability to utilize haemoglobin compared to strain HI1717 (Fig. 2). At higher concentrations of haemoglobin $\left(5 \mu \mathrm{g} \mathrm{ml}^{-1}\right)$ no significant difference in growth was seen (data not shown). A derivative of the hgp hup mutant strain complemented by a plasmid-encoded copy of hup (strain HI1953) was also compared to the wildtype strain for growth in $1 \mu \mathrm{g}$ haemoglobin $\mathrm{ml}^{-1}$ : strain

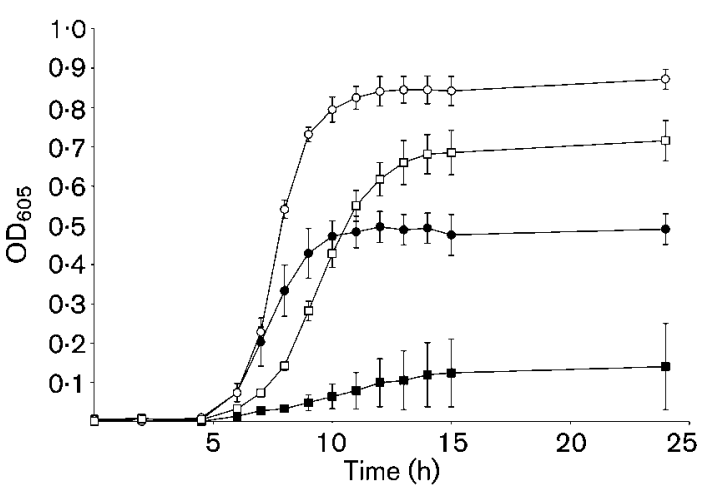

Fig. 2. Growth of the hgpABC triple mutant strain HI1717 and the hgpABC hup quadruple mutant strain $\mathrm{Hl} 1738$ in hdBHI supplemented with haemoglobin. Results are for HI1717 in $1 \mu \mathrm{g}$ haemoglobin $\mathrm{ml}^{-1}(\mathbf{O})$, Hl1738 in $1 \mu \mathrm{g}$ haemoglobin $\mathrm{ml}^{-1}$ (ש), HI1717 in $2 \mu \mathrm{g}$ haemoglobin $\mathrm{ml}^{-1}(\bigcirc)$ and HI1738 in $2 \mu \mathrm{g}$ haemoglobin $\mathrm{ml}^{-1}(\square)$. Results are mean \pm SD for triplicate results from a representative experiment. Using the KruskalWallis test over the entire growth period to compare strains $\mathrm{HI} 1717$ and HI1738: at $1 \mu \mathrm{g}$ haemoglobin $\mathrm{ml}^{-1}, P<0.0001$; at $2 \mu \mathrm{g}$ haemoglobin $\mathrm{ml}^{-1}, P=0.0032$.

HI1953 grew as well as the wild-type strain HI689 in $1 \mu \mathrm{g}$ haemoglobin $\mathrm{ml}^{-1} \quad(P=0.9918$ for one experiment, $P=0.9506$ for a second experiment). The hgp hup mutant strain carrying the plasmid vector alone was unaltered in its ability to utilize haemoglobin (data not shown).

Hup may represent a high-affinity haemoglobin-acquisition system. The effect of deletion of hup is not significant at high haemoglobin concentrations, indicating that an additional low-affinity haemoglobin-utilization system may exist. Mutants lacking the Hgp proteins and/or Hup retain the ability to bind haemoglobin in a dot-blot binding assay (data not shown), supporting the hypothesis that additional specific haemoglobin-binding proteins may be present. However, the LPS of other members of the Pasteurellaceae and the Enterobacteriaceae bind haemoglobin (Belanger et al., 1995; Grenier et al., 1997; Jürgens et al., 2001), although this binding has not been shown to be involved in a haemoglobin-utilization pathway. The LPS of $H$. influenzae may be responsible for the residual haemoglobin binding.

While performing growth studies with haemoglobin as the haem source, growth was also monitored with $10 \mu \mathrm{g}$ haem $\mathrm{ml}^{-1}$ as a positive control. The hgp hup deletion mutant, HI1738, showed a consistent and reproducible delay in the onset of growth as compared to the hgp mutant HI1717, with the difference in growth between HI1717 and HI1738 being statistically significant between 6 and $11 \mathrm{~h}$ in two independent experiments $(P=0.0162$ for one experiment, $P=0.0247$ for a second experiment). This observation led us to further examine the impact of the deletion of hup on the utilization of haem. 


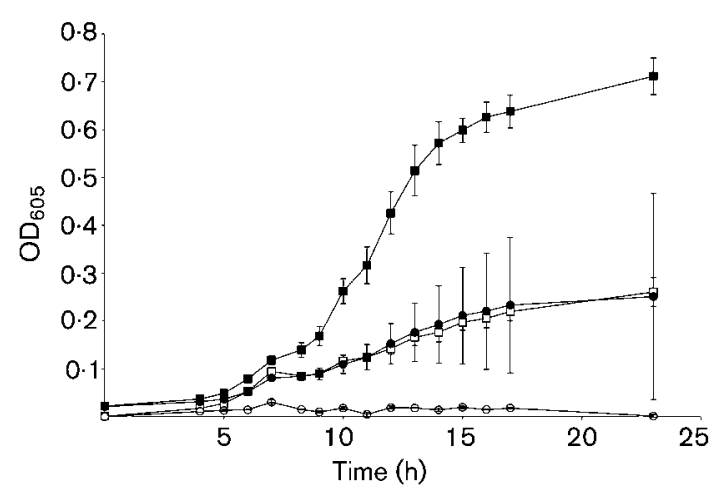

Fig. 3. Growth of the hgpABC triple mutant strain HI1717 and the hgpABC hup quadruple mutant strain $\mathrm{H} 11738$ in $\mathrm{hdBHI}$ supplemented with haem. Results are for HI1717 in $5 \mu \mathrm{g}$ haem $\mathrm{ml}^{-1}(\boldsymbol{\square}), \mathrm{Hl} 1717$ in $2 \mu \mathrm{g}$ haem $\mathrm{ml}^{-1}(\square), \mathrm{Hl} 1738$ in $5 \mu \mathrm{g}$ haem $\mathrm{ml}^{-1}(\bigcirc)$ and $\mathrm{HI} 1738$ in $2 \mu \mathrm{g}$ haem $\mathrm{ml}^{-1}(\bigcirc)$. Results are mean \pm SD for triplicate results from a representative experiment. Using the Kruskal-Wallis test over the entire growth period to compare strains $\mathrm{HI} 1717$ and HI1738: at $5 \mu \mathrm{g}$ haem $\mathrm{ml}^{-1}, P=0.0003$; at $2 \mu \mathrm{g}$ haem $\mathrm{ml}^{-1}, P<0.0001$.

The hgp hup deletion mutant grew significantly less well than the hgp mutant HI1717 in limiting levels of haem (Fig. 3). In addition, the single hup mutant strain HI1737 grew significantly less well than the wild-type strain HI689 in both $5 \mu \mathrm{g}$ haem $\mathrm{ml}^{-1}$ and $2 \mu \mathrm{g}$ haem $\mathrm{ml}^{-1}$ (Fig. 4). However, in contrast to the delayed growth of strain HI1738 as compared to strain HI1717, strain HI1737 grew as well as the wild-type strain in $10 \mu \mathrm{g}$ haem $\mathrm{ml}^{-1}$ (Fig. 4). Comparison of a complemented hup mutant strain (HI1955) with the wild-type strain and the hup mutant strain HI1737 for growth in $2 \mu \mathrm{g}$ haem ml $\mathrm{m}^{-1}$ demonstrated that the growth defect was at least partially restored by the presence of hup in trans (Fig. 4). Although the complemented strain HI1955 consistently grew to a lower final $\mathrm{OD}_{605}$ than the wild-type strain, the difference in growth over the entire curve was not statistically significant $(P=0.081$ for the experiment shown in Fig. $4 \mathrm{~b}$, $P=0.2159$ and $P=0 \cdot 0705$, respectively, for two independent experiments). In contrast the complemented strain HI1955 grew significantly better than the hup mutant strain HI1737 $(P<0.0001$ for the experiment shown in Fig. 4, $P=0.0005$ and $P=0.0092$, respectively, for two independent experiments). Strain HI1737 containing the plasmid vector pSU2718 was unaltered in its growth characteristics (data not shown).

The lower final $\mathrm{OD}_{605}$ consistently reached by HI1955 as compared to the wild-type strain may result from toxicity of Hup in increased copy number or alternatively from toxicity due to rapid accumulation of haem. However, growth in haemoglobin of an hgp hup mutant complemented with hup in multicopy did not result in a similar reduction in final $\mathrm{OD}_{605}$ compared to the wild-type. Complementation of hup with a single chromosomal copy elsewhere in the
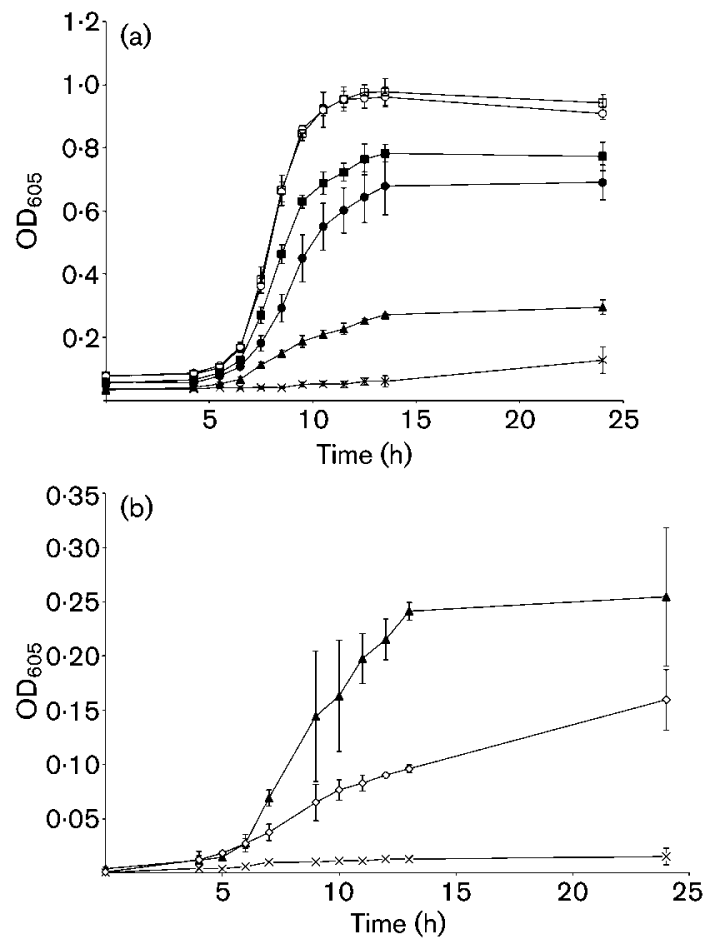

Fig. 4. (a) Growth of the wild-type strain HI689 and the hup single mutant strain $\mathrm{HI} 1737$ in hdBHI supplemented with haem. Results are for HI689 in $10 \mu \mathrm{g}$ haem ml ${ }^{-1}(\bigcirc), \mathrm{HI} 689$ in $5 \mu \mathrm{g}$ haem $\mathrm{ml}^{-1}(\boldsymbol{\square}), \mathrm{H} 689$ in $2 \mu \mathrm{g}$ haem $\mathrm{ml}^{-1}(\boldsymbol{A}), \mathrm{H} 1737$ in $10 \mu \mathrm{g}$ haem $\mathrm{ml}^{-1}(\square), \mathrm{H} 1737$ in $5 \mu \mathrm{g}$ haem $\mathrm{ml}^{-1}(\mathbf{O})$ and $\mathrm{HI} 1737$ in $2 \mu \mathrm{g}$ haem $\mathrm{ml}^{-1}(\times)$. Results are mean $\pm \mathrm{SD}$ for triplicate results from a representative experiment. Using the Kruskal-Wallis test: for HI689 versus HI1737 at $10 \mu \mathrm{g}$ haem $\mathrm{ml}^{-1}$ over the entire growth curve, $P=0.9059$; for HI689 versus $\mathrm{Hl} 1737$ at $5 \mu \mathrm{g}$ haem $\mathrm{ml}^{-1}$ over the entire growth curve, $P=0.11$, and from $6.5 \mathrm{~h}$ to $24 \mathrm{~h}, P=0.0204$; for $\mathrm{HI689}$ versus $\mathrm{HI} 1737$ at $2 \mu \mathrm{g}$ haem $\mathrm{ml}^{-1}$ over the entire growth curve, $P<0.0001$. (b) Growth of the wild-type strain HI689 (A), the hup single mutant strain $\mathrm{HI} 1737(x)$ and the hup mutant strain harbouring the hup-bearing plasmid pDJM367 (strain HI1955; $\diamond)$ in hdBHI supplemented with $2 \mu \mathrm{g}$ haem $\mathrm{ml}^{-1}$. Results are mean $\pm S D$ for triplicate results from a representative experiment. Using the Kruskal-Wallis test: for HI689 versus HI1955, $P=0.081$; for HI689 versus HI1737, $P<0.0001$; for Hl1955 versus $\mathrm{HI1737,} P<0.0001$.

chromosome might resolve this question; however, repeated attempts to construct such a strain have failed. Although it could not be statistically verified, we consistently observed an apparently faster initial rate of growth of strain HI1955 as compared to the wild-type strain HI689, possibly indicating more rapid accumulation of haem.

These data indicate that Hup is a component of a high-affinity haem-acquisition system. Deletion of hup alone had no effect on growth in high levels of haem (Fig. 4), while growth at low haem levels was significantly impacted, indicating that an additional low-affinity uptake 
mechanism(s) for haem exists. This may explain why mutation of the hup homologue in N. meningitidis (TdfH) was reported to have no effect on haem utilization (Turner et al., 2001); studies in limiting haem may demonstrate a role for TdfH in haem utilization. Comparison of the data for the impact of deletion of hup alone and combined with an hgp deletion at high levels of haem indicate a possible role for the Hgp proteins in haem acquisition; however, it is possible that the delay in onset of growth of the hgp/hup deletion mutant (HI1738) results from a generally less robust organism rather than a specific effect of $h g p$ deletion on haem acquisition. Comparison of the growth of strains HI689 and HI1717 in limiting levels of haem (Figs 3 and 4) demonstrated that the triple hgp deletion mutant (HI1717) grew significantly less well than the wild-type $(P=0.0197$ at $5 \mu \mathrm{g}$ haem $\mathrm{ml}^{-1}$ ), similarly indicating a potential role for the Hgp proteins in haem utilization that warrants further investigation.

In view of the demonstrated role of Hup in the utilization of both haem and haemoglobin, its potential role in the utilization of additional haem sources known to be used by $H$. influenzae in vitro (haem-haemopexin, haem-albumin and haemoglobin-haptoglobin) (Stull, 1987) was investigated. While the wild-type strain utilized haem-haemopexin as a haem source, the hup deletion mutant strain was unable to grow with haem-haemopexin as the sole haem source (Fig. 5). Similarly the hup deletion mutant was unable to utilize haemoglobin-haptoglobin $(1 \mu \mathrm{g}$ haemoglobin equivalent $\mathrm{ml}^{-1}$ ) as a haem source (Kruskal-Wallis test over entire growth curve comparing HI689 and HI1737 $P<0 \cdot 0001)$ (data not shown). Growth of the hup deletion mutant with haem-albumin as the sole haem source was significantly delayed as compared to the wild-type strain; however, the mutant strain eventually grew to the same bacterial density as the wild-type strain (Fig. 6).

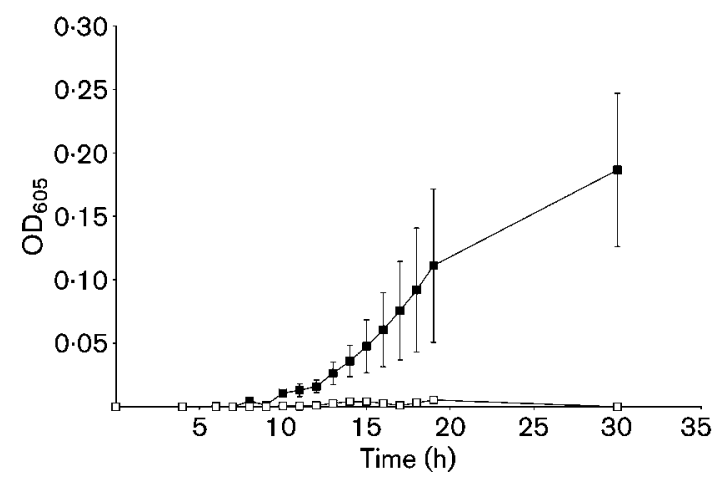

Fig. 5. Growth of the wild-type strain HI689 (ם) and the hup single mutant strain $\mathrm{HI} 1737(\square)$ in hdBHI supplemented with haem-haemopexin at $200 \mathrm{ng}$ haem equivalent $\mathrm{ml}^{-1}$. Results are mean \pm SD for triplicate results from a representative experiment. Using the Kruskal-Wallis test over the entire growth curve $P<0.0001$.
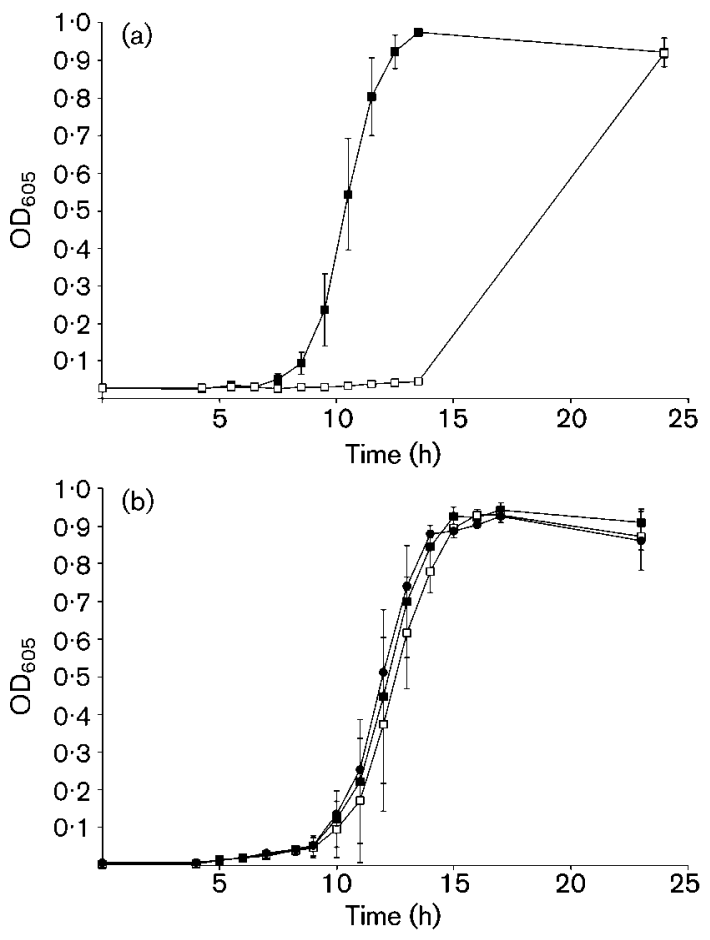

Fig. 6. (a) Growth of the wild-type strain HI689 (ם) and the hup single mutant strain $\mathrm{HI} 1737(\square)$ in hdBHI supplemented with haem-albumin at $1 \mu \mathrm{g}$ haem equivalent $\mathrm{ml}^{-1}$. Results are mean \pm SD for triplicate results from a representative experiment. Using the Kruskal-Wallis test over the entire growth curve, $P<0.0001$. (b) Growth of the wild-type strain HI689 (ם), the wild-type strain HI689 after prior passage through haemalbumin ( $\square$ ) and the hup single mutant strain HI1737 after prior passage through haem-albumin ( $)$ in hdBHI supplemented with haem-albumin at $1 \mu \mathrm{g}$ haem equivalent $\mathrm{ml}^{-1}$. Results are mean $\pm S D$ for triplicate results from a representative experiment. Using the Kruskal-Wallis test over the entire growth curve none of the differences between these data were statistically significant.

Stationary-phase organisms from the hup mutant growth curve in haem-albumin were recovered and their antibioticresistance profile confirmed. These recovered organisms were subsequently compared to the wild-type strain for growth in haem-albumin (Fig. 6). The mutant strain (HI1737) previously passaged through haem-albumin was indistinguishable in its growth in haem-albumin from the wild-type strain. Additionally, the complemented strain HI1955 grew as well as the wild-type strain $(P=0.7863$ and $P=0.2141$ for two independent experiments) and significantly better than the hup mutant strain HI1737 $(P=0 \cdot 0061$ and $P=0.0038$ for two independent experiments) with haem-albumin as the sole haem source.

The initially observed growth difference between the hup deletion mutant and the wild-type strain demonstrate a role for Hup in the utilization of haem-albumin. However, the eventual growth of the mutant indicates an additional 
Hup-independent pathway for acquisition of haem from haem-albumin. The growth of the haem-albumin-passaged hup deletion mutant at wild-type levels suggests that the alternative haem-albumin-acquisition pathway may be phase variable; a similar phenomenon is observed with growth in haemoglobin-haptoglobin and is attributable to one or more of the Hgp proteins shifting from an unexpressed state to an expressed state due to a frame alteration caused by strand slippage across a length of CCAA nucleotide repeats in the gene (Morton et al., 1999; Ren et al., 1999). The change in haem-albumin phenotype is not due to alteration in expression of the Hgp proteins, since growth of the hgp hup quadruple mutant gives the same results as reported above for the hup single mutant (data not shown).

It should be noted that the delay in onset of growth in the hup mutant strain varies widely in length between independent experiments; we have seen delays varying from $3 \mathrm{~h}$ up to $10 \mathrm{~h}$, possibly reflecting the percentage of cells expressing the putative phase-variable moiety in a given inoculum. No candidate phase-variable genes were identified in the available $H$. influenzae genomic sequences; however, the moiety responsible for the haem-albumin growth phenomenon observed in HI689 may not be present in the sequenced strains. Thus, it is not possible to identify the additional haem-albumin-acquisition pathway at this time.

The precise role of Hup in the acquisition of haem cannot be deduced at this time, although its apparent role in the acquisition of haem from several haem sources indicates that it may act as part of a central pathway through which haem from various sources is internalized. Whether Hup acts as a specific outer-membrane receptor for any particular haem source is not clear; although we initially isolated Hup in a haemoglobin affinity protocol this may reflect more an affinity for the haem moiety rather than specific binding of haemoglobin. Whole-cell haemoglobin-binding assays with the hup and hup hgp deletion mutants have not resolved this issue.

The failure of the hup deletion mutant to grow with haemoglobin-haptoglobin indicates that Hup may act as an accessory protein for the Hgp proteins, possibly by facilitating removal of haem from the protein complex or transporting haem across the outer membrane. The impact of deletion of hup on haem-haemopexin-utilization indicates a possible interaction between HxuC and Hup since $h x u C$ mutations also result in an inability of the mutant to grow on haem-haemopexin (Cope et al., 1995). The possible interaction between Hup and $\mathrm{HxuC}$ is further supported by the failure of both an hup mutant and an $h x u C$ mutant (Cope et al., 1995) to grow on low levels of free haem. Similarly both hup and hxuC (Cope et al., 2001) mutant strains are deficient in the ability to utilize haemoglobin when the hgp genes have also been deleted. Haem-albumin-utilization is also impacted by mutations in either hup or $h x u C$, although non-Hup-mediated acquisition mechanisms for this haem source also exist. These data point to a central role for Hup in haem acquisition by $H$. influenzae, possibly in association with HxuC and/or the Hgp proteins. We hypothesize that Hup is an accessory protein for specific outer-membrane protein receptors to remove haem from various haem-binding proteins. Additional work is under way to clarify the role of Hup and to define its interactions with other haemacquisition proteins and/or pathways.

\section{Contribution of Hup to virulence in the infant rat model of invasive infection}

To determine whether Hup contributes significantly to the virulence of $H$. influenzae in the infant rat model of invasive disease, a cohort of 5-day-old rat pups was infected with the wild-type strain HI689, the hup deletion mutant (HI1737), the hgp deletion mutant (HI1717) or the hup/hgp mutant (HI1738). At an infective dosage of 200 c.f.u., each of the strains was highly effective in establishing bacteraemia. All animals $(10 / 10)$ infected with each strain became bacteraemic within $24 \mathrm{~h}$ after infection. The antibiotic-resistance profile of recovered organisms was determined to ensure that the infecting organism was the correct strain.

The magnitudes of bacteraemia produced by the wild-type strain HI689 and the hup deletion strain HI1737 were indistinguishable (data not shown). Although both the hgp deletion strain (HI1717) and the hup/hgp deletion mutant (HI1738) exhibited a trend towards a reduction in bacteraemic titre on days 1 to 3 post-infection, none of the bacteraemic titres produced by these strains differed in a statistically significantly manner from those produced by challenge with the wild-type strain. Clearance of bacteraemia also did not differ among rat pups infected with the different strains; no infant rats cleared their bacteraemia over the 7-day period of this experiment. Similarly the clinical effect of all $H$. influenzae strains was indistinguishable. All animals had significant tremor 3 to 5 days postinfection (an indication of meningitis) but none was hypothermic to touch, exhibited anorexia, had a slow righting reflex or showed depressed locomotor activity.

These data indicate that expression of Hup is not required for establishment and maintenance of infection in the infant rat model of invasive disease. Since neither the Hgp proteins nor Hup are necessary for infection in this model it is unlikely that either haemoglobin-haptoglobin or haem-haemopexin are necessary haem sources in this model of invasive disease. It is possible that the $H$. influenzae haemoglobin-haptoglobin and/or haem-haemopexin uptake mechanisms are highly specific for the haem-binding proteins from the natural host species; if $H$. influenzae is unable to utilize haemoglobinhaptoglobin or haem-haemopexin from the rat then mutation of the acquisition pathways would not be expected to affect pathogenicity in this model.

No data are available on the relative ability of $H$. influenzae to utilize haemoglobin-haptoglobin complexes from 
different mammalian sources; $H$. influenzae can utilize haem-haemopexin complexes from both humans and rabbits (Wong et al., 1994), but no data are available with respect to rat haemopexin. It is clear from growth studies reported above that either haemoglobin or haem-albumin can be utilized by the hup and the hup hgp mutants in vitro; either haemoglobin or haem-albumin may represent a significant haem source during invasive disease in the 5-day old infant rat. $H$. influenzae grows well in vitro on haemoglobin from a wide range of mammalian sources including the rat, but it is not known if $H$. influenzae can utilize rat haem-albumin complexes as an in vitro haem source. Studies on the relative abilities of $H$. influenzae to utilize haem sources from various mammalian sources would be of potential value in analysing in vivo data.

We have recently shown that an Hgp deletion mutant of a nontypable strain has reduced virulence in a chinchilla model of otitis media (Morton et al., 2004), in contrast to the Hgp deletion mutant of a type b strain in the infant rat. That report indicates that haemoglobin-haptoglobin may be a primary source of haem in the middle ear of the chinchilla with experimentally induced otitis media. These data illustrate that both the complexity of the $H$. influenzae haem-acquisition systems and the potential for variable haem sources at different infection sites in the host render studies on the in vivo impact of mutations in the $H$. influenzae haem-acquisition pathways difficult. The findings reported here with respect to the lack of importance of Hup in the infant rat model of invasive disease do not preclude its relevance in other sites of disease and/or colonization.

In summary, the newly identified haem-utilization protein, Hup, may be an important cofactor in mediating haem acquisition from multiple human haem sources.

\section{ACKNOWLEDGEMENTS}

This work was supported by Public Health Service Grant AI29611 from the National Institute of Allergy of Infectious Disease to T. L. S., D. J. M and P.W.W. We gratefully acknowledge the support of the Children's Medical Research Institute.

\section{REFERENCES}

Bajanca, P., Canica, M. \& the Multicenter Study Group (2004). Emergence of nonencapsulated and encapsulated non-b-type invasive Haemophilus influenzae isolates in Portugal (1989-2001). J Clin Microbiol 42, 807-810.

Belanger, M., Begin, C. \& Jacques, M. (1995). Lipopolysaccharides of Actinobacillus pleuropneumoniae bind pig hemoglobin. Infect Immun 63, 656-662.

Cope, L. D., Yogev, R., Muller-Eberhard, U. \& Hansen, E. J. (1995). A gene cluster involved in the utilization of both free heme and heme: hemopexin by Haemophilus influenzae type b. J Bacteriol 177, 2644-2653.

Cope, L. D., Thomas, S. E., Hrkal, Z. \& Hansen, E. J. (1998). Binding of heme-hemopexin complexes by soluble HxuA protein allows utilization of this complexed heme by Haemophilus influenzae. Infect Immun 66, 4511-4516.

Cope, L. D., Hrkal, Z. \& Hansen, E. J. (2000). Detection of phase variation in expression of proteins involved in hemoglobin and hemoglobin-haptoglobin binding by nontypeable Haemophilus influenzae. Infect Immun 68, 4092-4101.

Cope, L. D., Love, R. P., Guinn, S. E., Gilep, A., Usanov, S., Estabrook, R. W., Hrkal, Z. \& Hansen, E. J. (2001). Involvement of HxuC outer membrane protein in utilization of hemoglobin by Haemophilus influenzae. Infect Immun 69, 2353-2363.

Evans, R. W., Crawley, J. B., Joannou, C. L. \& Sharma, N. D. (1999). Iron proteins. In Iron and Infection: Molecular, Physiological and Clinical Aspects, pp. 27-86. Edited by J. J. Bullen \& E. Griffiths. New York: Wiley \& Sons.

Fleischmann, R. D., Adams, M. D., White, O. \& 37 other authors (1995). Whole-genome random sequencing and assembly of Haemophilus influenzae Rd. Science 269, 496-512.

Foxwell, A. R., Kyd, J. M. \& Cripps, A. W. (1998). Nontypeable Haemophilus influenzae: pathogenesis and prevention. Microbiol Mol Biol Rev 62, 294-308.

Genco, C. A. \& Dixon, D. W. (2001). Emerging strategies in microbial haem capture. Mol Microbiol 39, 1-11.

Gray-Owen, S. D. \& Schryvers, A. B. (1996). Bacterial transferrin and lactoferrin receptors. Trends Microbiol 4, 185-191.

Grenier, D., Leduc, A. \& Mayrand, D. (1997). Interaction between Actinobacillus actinomycetemcomitans lipopolysaccharides and human hemoglobin. FEMS Microbiol Lett 151, 77-81.

Griffiths, E. (1999). Iron in biological systems. In Iron and Infection: Molecular, Physiological and Clinical Aspects, pp. 1-26. Edited by J. J. Bullen \& E. Griffiths. New York: Wiley \& Sons.

Gromkova, R. C., Rowji, P. B. \& Koornhof, H. J. (1989). Induction of competence in nonencapsulated and encapsulated strains of Haemophilus influenzae. Curr Microbiol 19, 241-245.

Hviid, A. \& Melbye, M. (2004). Impact of routine vaccination with a conjugate Haemophilus influenzae type b vaccine. Vaccine 22, 378-382.

Jett, B. D., Hatter, K. L., Huycke, M. M. \& Gilmore, M. S. (1997). Simplified agar plate method for quantifying viable bacteria. Biotechniques 23, 648-650.

Jin, H., Ren, Z., Pozsgay, J. M., Elkins, C., Whitby, P. W., Morton, D. J. \& Stull, T. L. (1996). Cloning of a DNA fragment encoding a hemerepressible hemoglobin-binding outer membrane protein from Haemophilus influenzae. Infect Immun 64, 3134-3141.

Jin, H., Ren, Z., Whitby, P. W., Morton, D. J. \& Stull, T. L. (1999). Characterization of $h g p A$, a gene encoding a hemoglobin/hemoglobinhaptoglobin-binding protein of Haemophilus influenzae. Microbiology 145, 905-914.

Jürgens, G., Müller, M., Koch, M. H. J. \& Brandenburg, K. (2001). Interaction of hemoglobin with enterobacterial lipopolysaccharide and lipid A. Physicochemical characterization and biological activity. Eur J Biochem 268, 4233-4242.

Laemmli, U. K. (1970). Cleavage of structural proteins during the assembly of the head of bacteriophage T4. Nature 227, 680-685.

Loeb, M. R. (1995). Ferrochelatase activity and protoporphyrin IX utilization in Haemophilus influenzae. J Bacteriol 177, 3613-3615.

Loosmore, S. M., Yang, Y., Coleman, D. C., Shortreed, J. M., England, D. M., Harkness, R. E., Chong, P. S. \& Klein, M. H. (1996). Cloning and expression of the Haemophilus influenzae transferrin receptor genes. Mol Microbiol 19, 575-586.

Marchler-Bauer, A., Anderson, J. B., DeWeese-Scott, C. \& 24 other authors (2003). CDD: a curated Entrez database of conserved domain alignments. Nucleic Acids Res 31, 383-387. 
Martinez, E., Bartolome, B. \& de la Cruz, F. (1988). pACYC184derived cloning vectors containing the multiple cloning site and lacZ alpha reporter gene of pUC8/9 and pUC18/19 plasmids. Gene 68, 159-162.

Morton, D. J. \& Stull, T. L. (1999). Distribution of a family of Haemophilus influenzae genes containing CCAA nucleotide repeating units. FEMS Microbiol Lett 174, 303-309.

Morton, D. J. \& Stull, T. L. (2004). Haemophilus. In Iron Transport in Bacteria: Molecular Genetics, Biochemistry, Microbial Pathogenesis and Ecology (in press). Edited by J. H. Crosa \& S. M. Payne. Washington, DC: American Society for Microbiology.

Morton, D. J. \& Williams, P. (1989). Utilization of transferrin-bound iron by Haemophilus species of human and porcine origins. FEMS Microbiol Lett 53, 123-127.

Morton, D. J., Whitby, P. W., Jin, H., Ren, Z. \& Stull, T. L. (1999). Effect of multiple mutations in the hemoglobin- and hemoglobinhaptoglobin-binding proteins, HgpA, HgpB, and HgpC of Haemophilus influenzae type b. Infect Immun 67, 2729-2739.

Morton, D. J., Bakaletz, L. O., Jurcisek, J. A., VanWagoner, T. M., Seale, T. W., Whitby, P. W. \& Stull, T. L. (2004). Reduced severity of middle ear infection caused by nontypeable Haemophilus influenzae lacking the hemoglobin/hemoglobin-haptoglobin binding proteins (Hgp) in a chinchilla model of otitis media. Microb Pathog 36, 25-33.

Murphy, T. F. (2003). Respiratory infections caused by non-typeable Haemophilus influenzae. Curr Opin Infect Dis 16, 129-134.

Musser, J. M., Barenkamp, S. J., Granoff, D. M. \& Selander, R. K. (1986). Genetic relationships of serologically nontypable and serotype b strains of Haemophilus influenzae. Infect Immun 52, 183-191.

Panek, H. \& O'Brian, M. R. (2002). A whole genome view of prokaryotic haem biosynthesis. Microbiology 148, 2273-2282.

Peters, T. (1996). All About Albumin: Biochemistry, Genetics, and Medical Applications. New York: Academic Press.

Ren, Z., Jin, H., Morton, D. J. \& Stull, T. L. (1998). hgpB, a gene encoding a second Haemophilus influenzae hemoglobinand hemoglobin-haptoglobin-binding protein. Infect Immun 66, 4733-4741.

Ren, Z., Jin, H., Whitby, P. W., Morton, D. J. \& Stull, T. L. (1999). Role of CCAA nucleotide repeats in regulation of hemoglobin and hemoglobin-haptoglobin binding protein genes of Haemophilus influenzae. J Bacteriol 181, 5865-5870.

Ribeiro, G. S., Reis, J. N., Cordeiro, S. M. \& 10 other authors (2003). Prevention of Haemophilus influenzae type b (Hib) meningitis and emergence of serotype replacement with type a strains after introduction of Hib immunization in Brazil. J Infect Dis 187, 109-116.

Schlor, S., Herbert, M., Rodenburg, M., Blass, J. \& Reidl, J. (2000). Characterization of ferrochelatase $($ hemH) mutations in Haemophilus influenzae. Infect Immun 68, 3007-3009.
Schryvers, A. B. \& Gray-Owen, S. (1992). Iron acquisition in Haemophilus influenzae: receptors for human transferrin. J Infect Dis 165 Suppl 1, S103-S104.

Sethi, S. \& Murphy, T. F. (2001). Bacterial infection in chronic obstructive pulmonary disease in 2000: a state-of-the-art review. Clin Microbiol Rev 14, 336-363.

Smith, A. (1985). Intracellular distribution of haem after uptake by different receptors. Haem-haemopexin and haem-asialo-haemopexin. Biochem J 231, 663-669.

Smith, A. \& Morgan, W. T. (1984). Hemopexin-mediated heme uptake by liver. Characterization of the interaction of hemehemopexin with isolated rabbit liver plasma membranes. J Biol Chem 259, 12049-12053.

Smith, A. L., Smith, D. H., Averill, D. R., Marino, J. \& Moxon, E. R. (1973). Production of Haemophilus influenzae $\mathrm{b}$ meningitis in infant rats by intraperitoneal inoculation. Infect Immun 8, 278-290.

St Geme, J. W. (2001). The pathogenesis of nontypable Haemophilus influenzae otitis media. Vaccine 19, S41-S50.

Stull, T. L. (1987). Protein sources of heme for Haemophilus influenzae. Infect Immun 55, 148-153.

Stull, T. L., Jacobs, R. F., Haas, J. E., Roberts, M. C., Wilson, C. B. \& Smith, A. L. (1984). Human serum bactericidal activity against Haemophilus influenzae type b. J Gen Microbiol 130, 665-672.

Tartof, K. D. \& Hobbs, C. A. (1988). New cloning vectors and techniques for easy and rapid restriction mapping. Gene 67, 169-182.

Turk, D. C. (1984). The pathogenicity of Haemophilus influenzae. J Med Microbiol 18, 1-16.

Turner, P. C., Thomas, C. E., Stojiljkovic, I., Elkins, C., Kizel, G., Ala'Aldeen, D. A. \& Sparling, P. F. (2001). Neisserial TonBdependent outer-membrane proteins: detection, regulation and distribution of three putative candidates identified from the genome sequences. Microbiology 147, 1277-1290.

VanWagoner, T. M., Whitby, P. W., Morton, D. J., Seale, T. W. \& Stull, T. L. (2004). Characterization of three new competence-regulated operons in Haemophilus influenzae. J Bacteriol 186, 6409-6421.

Ward, C. G. \& Bullen, J. J. (1999). Clinical and physiological aspects. In Iron and Infection: Molecular, Physiological and Clinical Aspects, pp. 369-450. Edited by J. J. Bullen \& E. Griffiths. New York: Wiley \& Sons.

Watt, J. P., Levine, O. S. \& Santosham, M. (2003). Global reduction of Hib disease: what are the next steps? Proceedings of the meeting Scottsdale, Arizona, September 22-25, 2002. J Pediatr 143, S163-S187.

White, D. C. \& Granick, S. (1963). Hemin biosynthesis in Haemophilus. J Bacteriol 85, 842-850.

Wong, J. C. Y., Holland, J., Parsons, T., Smith, A. \& Williams, P. (1994). Identification and characterization of an iron-regulated hemopexin receptor in Haemophilus influenzae type b. Infect Immun 62, 48-59. 